\title{
Using symbolic computation in Mathematica for verifying the convergence of the iterative methods
}

\section{GHEORGHE ARDELEAN}

\section{ABSTRACT.}

In [Jisheng Kou, The improvements of modified Newton's method, Appl. Math. Comput., 189 (2007) 602-609], the improvements of some thirdorder modifications of Newton's method for solving nonlinear equations are presented. In this paper we point out some flaws in the results of Jisheng Kou and we correct them by using symbolic computation in Mathematica. In [M. A. Noor et al., A new modified Halley method without second derivatives for nonlinear equations, Appl. Math. Comput., 189 (2007) 1268-1273] , the error equation obtained for the new method presented is wrong. We present the correct result by using symbolic computation, too. Finally, we present two examples of very simply proofs for the convergence of iterative methods by using symbolic computation. We consider that the Mathematica programs in this paper are good examples for other authors to prove the convergence of the iterative methods or to verify their results.

\section{REFERENCES}

[1] Ardelean, G., Proving the convergence of the iterative methods by using symbolic computation in Maple, Carpathian J. Math., 28 (2012), 1-8

[2] Cordero, A., Torregosa, J. R. and Vassileva, M. P., Three-step iterative methods with optimal eighth-order convergence, J. Comp. Appl. Math., 235 (2011), 3189-3194

[3] Džunić, J., Petković, M. S. and Petković, L. D., A family of optimal three-point methods for solving nonlinear equations using two parametric functions, Appl. Math. Comput., 217 (2011), 7612-7619

[4] Kou, J., The improvements of modified Newton's method, Appl. Math. Comput., 189 (2007), 602-609

[5] Li, X., Mu, C., Ma, J. and Wang, C., Sixteenth-order method for nonlinear equations, Appl. Math. Comput., 215 (2010), $3754-3758$

[6] Noor, M. A., Khan, W. A. and Hussain, A., A new modified Halley method without derivatives for nonlinear equations, Appl. Math. Comput., 189 (2007), 1268-1273

[7] Petković, M. S. and Petković, L. D., Families of optimal multipoint methods for solving nonlinear equations, Appl. Anal. Discrete Math., 4 (2010), $1-22$

[8] Traub, J. F., Iterative Methods for the Solution of Equations, Chelsea publishing company, New York, 1997

DEPARTMENT OF MATHEMATICS AND COMPUTER SCIENCE

FACUlty of SCIENCES NORTH University CENTER AT BAia MARE

TECHNICAL UNIVERSITY OF CLUJ-NAPOCA

VICTORIEI 76, 430122 BAIA MARE, ROMANIA

E-mail address: ardelean_g@yahoo.com 